\title{
Crew Exploration Vehicle Environmental Control and Life Support Fire Protection Approach
}

\author{
John F. Lewis, Richard Barido, and George C. Tuan \\ NASA Johnson Space Center
}

Copyright ( 2007 SAE International

\begin{abstract}
As part of preparing for the Crew Exploration Vehicle (CEV), the National Aeronautics and Space Administration (NASA) worked on developing the requirements to manage the fire risk. The new CEV poses unique challenges to current fire protection systems. The size and configuration of the vehicle resembles the Apollo capsule instead of the current Space Shuttle or the International Space Station. The smaller free air volume and fully cold plated avionic bays of the CEV requires a different approach in fire protection than the ones currently utilized. The fire protection approach discussed in this paper incorporates historical lessons learned and fire detection and suppression system design philosophy spanning from Apollo to the International Space Station. Working with NASA fire and materials experts, this approach outlines the best requirements for both the closed out area of the vehicle, such as the avionics bay, and the crew cabin area to address the unique challenges due to the size and configuration of the CEV.
\end{abstract}

\section{INTRODUCTION}

A fire event in a manned spacecraft is a serious concern. The small crew cabin combined with an elevated oxygen atmosphere can allow a fire to propagate quickly and poses a severe threat for the crew and vehicle. The Crew Exploration Vehicle (CEV) is going to have a smaller crew cabin volume than the current Space Shuttle and will see a higher oxygen concentration when going to the moon. Lunar missions will drive vehicle designs to have lower cabin atmospheric pressure and as a result, an enriched oxygen concentration in the environment. The Apollo Crew Module (CM) had an environment with $100 \%$ oxygen with a 6.4 psia atmosphere. The CEV is proposed to have a 30\% oxygen environment with a 10.4 psia atmosphere for lunar missions.
The enriched oxygen atmosphere and smaller cabin of the CEV requires rethinking the fire protection approach as compared to the current Space Shuttle and the International Space Station (ISS). Before looking at the CEV fire protection approach, an understanding of the historical and current fire protection systems that has been implemented on various NASA's manned space vehicle is essential. Incorporating past experiences and lessons is central to getting the best design.

\section{PAST AND PRESENT}

Historically, fire protection has incorporated three levels of protection: Fire Prevention, Fire Detection, and Fire Suppression. Fire Prevention is the first and most significant level of protection. It is based on the ability to design your vehicle and system in a way that minimizes the risk of fire ignition. This is the foundation of any vehicle's approach to managing fire related risks. Fire Detection is the ability to detect a in the unfortunate case that a fire is ignited. The faster the fire is detected, the faster a response can be made and the damage limited. In space however, fire detection is not a simple task, as smoke and heat do not rise up in microgravity. Fire Suppression is the final level of protection and is there when the worst of the worst happens. The ability to stop and put out a fire as quickly as possible without putting the crew in danger is crucial for keeping the vehicle and crew safe.

To understand how each of the three levels of protection work with one another and enable a successful fire protection strategy, a historical look at previous manned vehicles is beneficial for selecting the most effective fire protecting approach for the CEV. The following historical look at Mercury, Gemini, Apollo, Space Shuttle and ISS will only scratch the surface of the massive amount of studies and the years of developmental work behind each of the fire protection systems. 


\section{FIRE PREVENTION}

To understand how to prevent fires, one needs to first understand what is necessary for a fire to occur. Fire, both on the ground and in microgravity, requires three ingredients, as represented by the familiar fire triangle: fuel, ignition, and oxygen. Remove and controlling any of these ingredients necessary have been the foundation of fire prevention.

In Mercury, Gemini, and Apollo controlling the ingredients for a fire was difficult. All three of the vehicles were designed for $100 \%$ oxygen environment. Oxygen, necessary for crew survival, cannot be removed. Thus, Mercury and Gemini's fire protection strategy were state-or-the-art non-flammable materials of the time and safe practices to prevent any ignition source.

This was the approach until the Apollo 1 fire happened, when an unexpected ignition occurred and the state-ofthe-art materials were exposed to 16.2 psia $100 \%$ oxygen environment in which they had never been tested. After Apollo 1 fire, two major lessons were learned. The first is that no matter how well ignition source are controlled, an ignition source will always exist. The second is that materials flammability needs to be tested at the worst case conditions to which the material will be exposed. Subsequent to the accident, materials, components and subsystems were redesigned and tested to improve fire safety. Apollo still required a 6.2 psia $100 \%$ oxygen environment on orbit, but made the vehicle safer on the launch pad by limiting the oxygen concentration. Apollo went as far as building a complete $\mathrm{CM}$ mockup with flight materials and conducting CM level flammability tests.

The Space Shuttle and ISS both have strict material flammability requirements which are verified through standard tests. They also have a less hazardous atmosphere with a maximum of $25.9 \%$ oxygen at 14.7 psia and $30 \%$ oxygen at 10.2 psia. For materials that don't meet the flammability requirements, there is propagation path control where flammable materials are isolated from ignition sources or any other flammable material by a specific distance.

A major source of ignition sources on any space vehicles are electrical and electromechanical subsystems. The ISS, designed as a space laboratory, has high power busses and systems and they are kept fire safe not only by material selection but also ignition source control. This is done by using a Fault Detection, Isolation, and Recovery (FDIR) architecture and also Electrical, Electronic, and Electromechanical (EEE) part selection to meet de-rating and current protection requirements. FDIR detects and shuts down failures before ignition can occur in the subsystem while EEE part requirements assures properly selected parts and components to reduce risk of the parts becoming an ignition source.

\section{FIRE DETECTION}

When Mercury, Gemini, and Apollo were designed, fire detection technology was still immature and the most reliable system available was the crew nose. The fire protection strategy required the crew to detect a fire and take action to suppress it.

Skylab was the first manned vehicle to incorporate a fire detection method due to the larger volume and more complicated systems. It utilized a line-of-sight radiometer that detected ultraviolet wavelength generated by $\mathrm{OH}$ radicals generated by a fire.

The Space Shuttle was the first vehicle to use commercial ionization-type smoke detector. Unlike fire detectors on the ground, fire detector utilization in microgravity is difficult. Generally fire detection on the ground detects heat, smoke, flame, or particles, all of which are difficult to detect without movement of air. In the gravitational field of the earth, natural convection generates an upward airflow from the fire making detection easier. In microgravity, natural convection does not exist and forced air flow is required to allow for the use smoke/particle detectors. The Shuttle has several separate forced air loops in the various avionics bays and the crew cabin to generate the airflow required to transport smoke particles to the detector.

The ISS also utilizes the same fire detection strategy as the shuttle, using particulate smoke detectors in forced air loops. Instead of avionic bays, the ISS has avionics throughout housed in racks. Those racks that require forced air cooling for the avionics have built in particle detectors in the forced air loop. In the general crew area of the ISS, there are various particle smoke detectors placed throughout the various modules. CFD analysis is necessary to make sure the air ventilation rate in the modules will transport smoke particles to the detectors, making sure there isn't any object blocking the detectors.

\section{FIRE SUPPRESSION}

Fires can be suppressed in four basic methods: removing the fuel, removing the oxygen, cooling the reaction, or inhibiting the reaction chemically. All four methods have been used on various manned vehicles.

Mercury and Gemini had potable water available as a fire suppression method. There was no dedicated fire suppression system, but in the high oxygen concentration environment of these vehicles, water was the only effective suppressant. Water essentially cools the reaction and stops the fire from propagating. 
Apollo introduced a water and foam hand-held fire extinguisher which used cellulous gel to form the foam when sprayed. It works by cooling the reaction and stops the fire from propagating. The same type of water foam extinguisher was used by Skylab.

Space Shuttle introduced a halogenerated hydrocarbon (Halon) fire extinguisher. The advantage of the Halon fire extinguisher is that the gaseous base suppressant can be used to flood the crammed avionic bays with a chemical that inhibits further combustion chain reaction. This is more effective than a water foam extinguisher which would not be able to flood an avionics bay as effectively.

While the Halon fire extinguisher system receives more focus on the Shuttle, there is actually a fire response system that happens first. When a fire is detected on the Shuttle, the forced air system is shut down. The same microgravity effect that makes detection difficult is also a great fire suppression method. The lack of natural convection in microgravity can starve the fire of oxygen and extinguish it. As the fire burns and uses up the surrounding oxygen, there isn't any airflow to bring in new oxygen. Halon is used only after determining that the fire did not self extinguish.

The ISS also cuts off airflow at the detection of a fire. However, ISS does not use Halon fire suppression as Halon can not be effectively removed from the cabin air and there are long term issues with toxicity and corrosiveness of the halogen acids. ISS instead utilizes a carbon dioxide fire suppressor which when used can flood either avionics racks or modules with carbon dioxide and starve the fire of oxygen.

\section{CEV FIRE APPROACH}

One common fire protection approach for both past and present manned space vehicle is the separation of the avionics bay and the crew cabin. The same approach can be taken with the CEV Command Module, separating it into a crew cabin and the closed-out avionics bays. Because both areas have different air ventilation, configuration, and accessibility conditions, it is prudent to develop different fire protection strategies for each of these areas. The crew cabin, being the area where the crew resides, has strict air ventilation requirements and is composed of accessible, open space for the crew to live and work in. The closed-out avionics bay areas are crammed with high powered electrical and electromechanical systems on cold plates, and there is normally no air ventilation requirement and no crew accessibility requirement.

\section{CREW CABIN}

To begin any fire protection strategy, fire prevention is still the basis. This was done in Apollo era through strict material and ignition control and is still done to date. But it has also been recognized that strict use of nonflammable materials in the crewed area is always difficult. Some materials, like clothing and books, will be onboard even though they do not meet non-flammable requirements. But as long as they are kept a safe distance away from ignition sources the risk is greatly reduced. Strict ignition control in the crew cabin involves testing of electronic devices to insure fire containment and closing off high-powered avionics boxes and wire bundles from the cabin.

The crew habitable area has strict ventilation requirements to allow proper mixing and cooling of the cabin atmosphere. Ventilation is required while the crew is in the CEV, docked to the ISS, or docked to the Lunar Surface Access Module (LSAM). This ventilation allows and requires the use of a particle smoke detector similar to the Shuttle or ISS to shut down the ventilation at the detection of fire. As seen in previous experience, ventilation in microgravity will always increase fire propagation risk while the lack of ventilation increases self extinguishment. Shutting down air ventilation also protects the air revitalization system from toxic gases generated by the fire.

Due to the small size of the CEV crew cabin, a gaseous fire suppression system such as Halon or carbon dioxide poses a hazard to the crew. Not only is the high Halon exposure level risk for the crew, there is no way to remove the Halon except thorough depressurization of the cabin. Carbon dioxide levels required to suffocate a fire can also suffocate the crew. This leads the CEV to consider a water foam fire extinguisher in the crew cabin as in Apollo and Skylab. Water foam is highly effective when pointed at a fire and has the added advantages of cooling the heat generated by a fire event.

\section{CLOSED-OUT AVIONICS BAY}

The CEV CM, like Apollo, must have the capability to depressurize to vacuum. Due to this necessity, any high powered electrical or electromechanical devices that require cooling cannot rely on air ventilation cooling, instead they utilize cold plates. As a result, there is no forced air ventilation in the closed-out avionics bays making conventional particulate smoke detection impractical. Smoke detection is necessary in air ventilated avionics bay on the Shuttle and ISS to shut down the airflow, but in avionic bays that don't have forced air ventilation, particulate smoke detection isn't provided nor is it necessary.

Due to the lack of fire detection, avionics bays will rely on three levels of protection: FDIR system architecture, EEE parts de-rating and current protection, and nonflammable materials selection. This fire protection strategy for avionics bays is currently used on both 
Shuttle and ISS for racks that don't have forced air ventilation.

However, both the Shuttle and ISS racks have fire ports that allow the use of an external handheld fire extinguisher as a worst case precaution. To effectively use fire ports, two conditions must exist: the ability to quickly access the fire ports, and an effective fire extinguisher that can flood the avionic bay no matter where the fire is located. Both of these conditions are difficult to meet for the CEV. The CEV is a small vehicle with limited wall space. Fire port access requires the area surrounding the fire port to be kept clear at all times, limiting crew storage area and space. Waterfoam extinguishers are not as effective in flooding avionics bay volumes and as a result, a gas suppressant based fire extinguisher is necessary. The other option is to have a manually activated fire extinguisher in the close-out bays instead of using the fire ports. This will still allow the ability to have a backup fire suppression system that can be activated by the crew or by ground control if necessary.

The decision to activate the fire suppression system needs to be carefully considered. When discharging, gaseous based fire suppression will create forced airflow that can stir up an already dying fire giving it a second life before extinguishing it, or even worse, it can force a fire into a smoldering event that doesn't require oxygen. Generally, the fire extinguisher is only discharged when there is a confirmed fire event happening at the current time. If it can be sufficiently proven that the closed-out avionics bays in the worst case oxygen atmosphere with a fire ignition will not allow the fire to propagate due to materials selection and electrical and electromechanical enclosure design, then the fire suppression system is not necessary. One way to gain assurance that a fire will not propagate in a worst case environment is to add margin to the flammability requirement. For example, testing and using materials and equipment enclosures that are tested and proven to be nonflammable in a $40 \%$ oxygen, 10.2 psia atmosphere will give greater assurance for the material in a 30\% oxygen atmosphere.

\section{CONCLUSION}

A quick evaluation of past and present fire protection methods on different vehicle shows the evolving nature of fire protection methods. As technology and understanding of fires in microgravity progresses, new and better fire protection methods continue to be developed. The CEV will require a fire prevention strategy that is similar to the Apollo CM, while technology has allowed better Fire Detection and Suppression (FDS) systems than Apollo ever had. Utilizing new technologies and better understanding of fire in microgravity will enable the CEV to have a successful fire protection system while minimizing risk and dangers to the crew.

\section{ACKNOWLEDGEMENT}

The author of this paper would like to acknowledge and thank the many materials experts that have helped in developing the CEV Fire Strategy. They include Mike Pedley and John Graf of NASA Johnson Space Center, Gary Ruff and Dave Urban of NASA Glenn Research Center, and Harold Beeson and David Hirsch of NASA White Sands Test Facility.

\section{REFERENCE}

Need to add in references. 